Revista Signos
$2010 / 43$

Número Especial

Monográfico $\mathrm{N}^{\circ} 1$

143-159

\title{
Livros perigosos para garotos e maravilhosos para meninas: 0 gênero social diferenciando o gênero discursivo
}

\author{
Rosa Maria Hessel Silveira \\ Universidade Luterana do Brasil \\ Universidade Federal do Rio Grande do Sul \\ Brasil
}

Resumo: Livros de auto-ajuda constituem gênero discursivo em proliferação no mundo contemporâneo e nele podem ser enquadrados títulos direcionados para crianças, com conselhos, dicas, instruções de atividades, de comportamento e textos informativos. Entre tais livros, estão obras que se dirigem separadamente a meninos e meninas, como é o caso de 'O Maravilhoso Livro das Meninas' e 'O Livro Perigoso para Garotos'. Essas obras, ainda que tenham estrutura semelhante, diferem em função das representações culturais do leitor a ser atingido: meninos ou meninas. Nesse sentido, o objetivo do estudo é o de confrontar tais obras identificando nelas marcas distintivas que o gênero, como categoria social relacionada a sexo, imprime no gênero discursivo específico. Os estudos de gênero social e os estudos sobre gêneros discursivos fundamentam a análise. Conclui-se que há uma dicotomia de temáticas nos ensinamentos de como fazer, nas temáticas dos textos informativos e mesmo nas sugestões de livros e filmes.

Palabras-Chave: Gênero social, gênero discursivo, livros infantis, livros de auto-ajuda.

Recibido: 20-XI-2009

Aceptado: 24-V-2010
Correspondencia: Rosa Maria Hessel Silveira (rosamhs@terra.com.br). Universidade Luterana do Brasil. Universidade Luterana do Brasil. Av. Farroupilha 8001, Bairro São José, Canoas/RS. CEP 92425-900, Brasil. 


\title{
Libros peligrosos para niños y maravillosos para niñas: El género social distinguiendo el género discursivo
}

Resumen: Los libros de autoayuda constituyen un género discursivo en proliferación en el mundo contemporáneo y a esa clase de discurso se pueden incluir títulos direccionados hacia los niños, con consejos, pistas, instrucciones de actividades, de comportamiento y textos informativos. Entre estos libros están obras que se dirigen separadamente a niños y niñas, como es el caso de 'O Maravilhoso Livro das Meninas' y 'O Livro Perigoso para Garotos'. Esas obras, aunque tengan estructura semejante, se distinguen en lo que se refiere a las representaciones culturales del tipo de lector que se quiere alcanzar: niños o niñas. En esa dirección es que va el objetivo de ese estudio que será cotejar estas obras identificando en ellas rasgos distintivos que el género, como categoría social relacionada a sexo, imprime al género discursivo específicamente. Los estudios de género social y los estudios sobre géneros discursivos fundamentan el análisis. Se concluye que hay una dicotomía de temas en las enseñanzas del cómo hacer en los temas de los textos informativos y aun en las sugerencias de libros y películas.

Palabras Clave: Género social, género discursivo, libros infantiles, libros de autoayuda.

\section{Books that are dangerous for boys and glorious for girls: The social gender distinguishing the discourse genre}

\begin{abstract}
Self-help books are a discourse genre in proliferation in the contemporary world, and titles target children with counselling, suggestion for activities and behaviour; informative texts can also fit in it. Among these books are works addressing separately boys and girls, such as ' $O$ Maravilhoso Livro das Meninas' and ' $O$ Livro Perigoso para Garotos'. Although these works have similar structures, they differ in relation to the cultural representations of the intended reader: boys or girls. In this respect, this study aims at contrasting these works by identifying distinctive marks in them that gender, as a sex-related social category, affects this particular discourse genre. Studies of social gender and studies of discourse genres ground the analysis. It follows that there is a dichotomy of themes as far as how-to teaching in informative text themes is concerned as well as in recommendations of books and films.
\end{abstract}

Key Words: Social gender, discourse genre, children's books, self-help books.

\section{INTRODUÇÃO:}

\section{Um pouco sobre a história dos manuais, sobre gênero discursivo e sobre gênero social}

Manuais para crianças não constituem propriamente uma novidade na cultura ocidental. De certa forma, eles surgiram conectados à própria emergência da idéia de infância como grupo de sujeitos com características específicas, a serem cuidados, educados, formados e preservados das cruezas do mundo adulto, conforme nos mostram os estudos conhecidos de Ariès. 
Vale a pena relembrar a informação trazida por Postman (1999: 64), de que, no fim do século $\mathrm{XVI}$, na Europa, por não mais ser permitido que as crianças conhecessem "os segredos do comportamento público do adulto, os 'livros de boas maneiras' tornaram-se lugares-comuns" (grifo nosso). Vários pesquisadores identificam como precursor de tais compêndios a obra De Civilitate Morium Puerilium, de Erasmo de Rotterdam, publicada em 1530. Elias (1994: 69) afirma que este livro "trata de um assunto muito simples: o comportamento de pessoas em sociedade -e acima de tudo, embora não exclusivamente, 'do decoro corporal externo'”. A análise de Elias (1994) se demora em detalhes de conselhos que para nós soam hoje exóticos, como os referentes ao lugar onde as diferentes pessoas deviam enxugar o nariz, por exemplo, e o autor observa ainda que "grande parte do que ele [Erasmo] diz ultrapassa nosso patamar de delicadeza" (Elias, 1994: 72).

Evidentemente, o livro de Erasmo não foi o único da linhagem e houve uma produção generalizada na Europa de livros sobre boas maneiras. Apesar das dificuldades em encontrar fontes sobre a publicação e/ou circulação de 'manuais de civilidade' no século XIX no Brasil -século em que a imprensa e as editoras brasileiras iniciaram sua trajetória, foi possível identificar, no estudo de Hallewell (1985), a indicação da edição em 1865, de um 'Novo manual de bom tom, contendo moderníssimos preceitos de civilidade, polidez, conduta e maneiras em todas as circunstâncias da vida'. Embora não se trate de livro para crianças e jovens, ele assinala a continuidade da tradição de um gênero textual voltado para o aconselhamento de como 'se comportar', o que -em parte, como adiante veremos- irá desembocar nos dois livros para garotos e garotas que analisaremos. Carvalho (2009) nos informa sobre a publicação, no Brasil, pela Livraria Salesiana Editora, entre as décadas de 1920 e 1960, de um 'Compêndio de Civilidade', com um acento marcadamente católico, a ser adotado pelos colégios confessionais, a partir do entendimento de que a civilidade seria uma parte da caridade, uma das virtudes cristãs basilares.

Ainda que o termo 'civilidade' tenha caído em desuso em relação à educação das crianças e o próprio entendimento de desenvolvimento infantil e de educação adequada tenha sofrido importantes modificações no século XX, principalmente sob o influxo do campo da Psicologia, é impossível ignorar os laços que existem entre o objetivo de tais manuais e o dos livros a serem examinados no presente trabalho.

Podemos nos inquirir, neste momento, sobre como se articularia o gênero discursivo-textual 'manual' com a atual literatura de 'auto-ajuda'.

Costa (2008: 131), em verbete sobre 'manual', afirma que tal gênero "caracteriza-se, em geral, pelo predomínio do discurso instrucional e didático, em que as orientações são dadas usando-se 
o imperativo, o infinitivo, sempre numa interlocução direta com o leitor". 0 autor observa que o manual pode ser uma obra de cunho didático, um livro que orienta a execução de uma tarefa ou técnica, um livreto de instruções de um produto. Ao esboçar as configurações do gênero, Costa (2008) propõe, quanto ao discurso, as seguintes características:

- discurso isento de ambigüidades;

- discurso que torna legítimas aspirações diversas a classes sociais e a épocas várias;

- discurso que oferece saberes e deveres idealizados;

- discurso no qual predomina a cena enunciativa de aconselhamento;

- discurso em que o enunciador manipula o leitor (enunciatário) em direção à aceitação de certos valores sociais, por exemplo, ou outros valores.

Meurer (1998), ao analisar aspectos da linguagem em um livro de auto-ajuda, propõe uma discussão específica sobre o 'aconselhamento' como gênero, a partir de Swales e Martin. 0 autor enfatiza, como principal critério para a definição dos gêneros em geral o propósito comunicativo, o que nos auxiliar a classificar como textos exortativos tanto os antigos manuais como os atuais livros de auto-ajuda.

Enfim, é evidente que há uma continuidade de características genéricas entre os antigos manuais (inclusive para crianças) e os textos e livros de auto-ajuda, produtos de extraordinária proliferação no mundo contemporâneo. De que forma os livros 'perigosos' e 'maravilhosos' para meninos e meninas se afastam dessas características ou se ajustam a elas é o que abordaremos adiante.

A essa breve reflexão sobre o gênero textual auto-ajuda, somaremos agora algumas considerações sobre o 'gênero social' ou 'cultural'. A partir de sua nomeação como 'gênero' (gender), fica evidente o afastamento da noção tradicional de 'sexo', entendido como diferenciação entre sujeitos baseada e previamente determinada por oposições biológicas. Para as estudiosas feministas, por exemplo, as distinções entre masculino e feminino são socialmente construídas, através do que é dito, esperado, imputado a um e outro sexo, conforme as épocas e os grupos sociais.

A idéia de gênero como uma construção social dos sexos está na base dos estudos de gênero (gender studies), campo que ganhou grande impulso teórico e de pesquisas nos últimos anos. Tais estudos provocaram a desnaturalização de inúmeras características consideradas como intrinsecamente pertencentes a mulheres e a homens. Preferências, disposições, pendores, formas de se comportar, falar e agir... variadas dimensões que constituem o 'ser homem' e 'ser mulher' no âmbito social mostraram-se como fruto de detalhadas e insistentes pedagogias culturais, atuantes na família, na escola, no grupo de pares, nos produtos da mídia. Tais peda- 
gogias, que têm um início muito precoce na vida dos sujeitos, atuam de forma tão poderosa que possibilitam poucos questionamentos a respeito do que seria o caráter biológico e inescapável da divisão dos gêneros.

É a partir da conjugação dessas duas vertentes -a do gênero textual dos manuais ou livros de auto-ajuda para a infância e a do gênero social que caracteriza como diferentes o masculino e o feminino- que se propõe a presente análise, cujo material empírico é a seguir descrito.

\section{Livros para meninos e meninas}

Encontramos, no panorama editorial dos últimos anos, alguns livros que, dirigindo-se a meninos e meninas separadamente, incorporam várias características do gênero 'manual' ou 'autoajuda', contendo conselhos, dicas, instruções de atividades, de comportamento e textos informativos, escolhidos para formação dos seus leitores e leitoras. Entre tais livros, escolhemos duas obras que, à primeira vista, se assemelham no gênero textual, direcionando-se a meninos ou meninas. Trata-se, em primeiro lugar, de 'O Maravilhoso Livro das Meninas', de autoria de Davidson e Vine sob o título original The great big glorious book for girls, com tradução para a língua portuguesa, no Brasil, publicada pela Editora Globo em 2008, e com tradução para Portugal, intitulada 'O Livro de Ouro das Raparigas Prendadas', editada também em 2008, pela Editora Casa das Letras. Em segundo lugar, analisamos 'O Livro Perigoso para Garotos', da autoria dos irmãos Iggulden e Iggulden, com tradução publicada no Brasil em 2007, pela Editora Record, e tradução para o espanhol com o título El Libro Peligroso para los Chicos, publicado pela Paidós Ibérica 2007. Conforme informações da própria editora, o 'Livro Perigoso para Garotos' já teria vendido mais de 1 milhão de exemplares na Inglaterra e nos Estados Unidos, tendo sido saudado com entusiasmo na mídia, por ocasião de seu lançamento no Brasil. Essas obras, ainda que tenham estrutura semelhante, apresentam diferenças em função das representações culturais do leitor a ser atingido: meninos ou meninas.

'O Livro Perigoso para Garotos' é um manual com capa dura vermelha com letras em preto e dourado e desenhos representando um jogador de futebol, uma bandeira de pirata, um dinossauro e um carrinho de rolimã. Possui 320 páginas, é ilustrado com desenhos e, eventualmente, fotos, apresentando 80 seções em que se intercalam textos declaradamente instrutivos, iniciados pela expressão 'como fazer...', textos informativos (sobre pescaria, sobre batalhas, sobre 'heróis', sobre Astronomia, sobre Gramática, etc.), vazados numa linguagem de fácil compreensão, e textos com sugestões de caráter mais formativo-cultural: 'Cinco poemas que todo garoto deveria conhecer', 'Livros que todo garoto deveria ler', 'Filmes que todo garoto deveria ver'. A tradução brasileira envolveu uma adaptação de vários itens, o que explica a 
presença de seções como as referentes a 'Batalhas famosas do Brasil', 'Os irmãos Villas-Bôas e a marcha para o Oeste', 'Brasil: Uma breve história', etc.

Já 'O Maravilhoso Livro das Meninas' tem um projeto editorial um pouco menos ambicioso, ainda que apresente praticamente o mesmo formato do congênere masculino. Sua capa não é dura e vem em tons de azul; sobre a mesma se veem silhuetas de crianças brincando de corda, numa espécie de gravura retrô, estética que atravessará todo o seu miolo. Possui 303 folhas impressas e suas ilustrações são todas de desenhos não coloridos. Contém 21 seções que, a exemplo do livro para meninos, se dedicam tanto a ensinar a fazer coisas ('Como fazer barra', 'Para tentar em casa [saltos de balê]', 'Como fazer lanterna de abóbora', etc.), quanto trazem informações ('Mulheres inspiradoras', 'Grandes amores', 'Direitos dos animais', etc.) e, finalmente, uma seção denominada 'Um pouco de cultura', onde se alinham sugestões de livros e de filmes.

Pois bem: é debruçando-nos sobre essas duas obras que estabelecemos como objetivo deste estudo confrontá-las, identificando nelas marcas distintivas que o gênero, como categoria social relacionada a sexo, imprime no gênero discursivo específico.

\section{0 que é bom para meninos e o que é bom para meninas -ensinamentos de 'como} fazer...'

Antes de evidenciarmos as diferenças entre conselhos e ensinamentos para meninos e para meninas, torna-se necessário apontar algumas coincidências entre o discurso das duas obras. Em primeiro lugar, há uma constante auto-referência e autolegitimação dos livros, com ênfase a seu caráter de atualidade, mesmo em tempos pós-modernos. Assim é que a introdução, chamada 'Eu não tinha este livro quando era garoto', de 'O Livro Perigoso para Garotos' (doravante, LPGo), assim inicia:

“Nesta época de videogames e telefones celulares, ainda deve haver lugar para amarrar nós, fazer casas em árvores e contar histórias de incrível coragem”; e, mais adiante, no mesmo texto, lê-se: "Elas [as histórias] fazem parte de uma cultura, uma parte que realmente não queremos que desapareça. / Tudo isso está fora de moda? Bem, depende”.

Já na Introdução de 'O Maravilhoso Livro das Meninas' (doravante, MLMa), a tônica é a universalidade e a continuidade de como as meninas são/eram:

"Enormes transformações se sucederam, e hoje todo mundo navega na internet, fala pelo celular e vê DVD. Mas, basicamente, as meninas continuam muito parecidas com as antepassadas da Idade da Pedra: ainda se encantam diante de um filhotinho de cachorro e preservam a capacidade de passar horas trocando de roupa em busca do visual perfeito. 
O mundo contemporâneo pode estar repleto de novidades tecnológicas, mas sobrevive intacto na alma humana o prazer de preencher as horas livres com o trabalho manual bem-feito ou a leitura de um belo romance".

É interessante observar que, malgrado a tônica comum -da perenidade dos interesses e de uma suposta 'essência' humana, não ameaçada pela tecnologia atual- já nas páginas iniciais se delineia o que será um dos eixos da divisão entre meninos e meninas: a intrepidez e a coragem dos meninos, e a sensibilidade, a vaidade e a afetividade das meninas.

Para perscrutarmos melhor tal diferenciação, verificaremos, em primeiro lugar, as áreas em que, de forma diferenciada, se situam os ensinamentos de 'como fazer' nos dois livros.

Para os meninos, o livro já se abre com um rol de ‘equipamentos básicos', que prenuncia o tom das receitas práticas que se seguirão: canivete suíço, bússola, lenço, caixa de fósforos, uma bola de gude, agulha e linha, lápis e papel, lanterna pequena, lente de aumento, curativos, anzóis. A partir daí, adentrando as seções espalhadas dentro do livro, os garotos leitores poderão ler e aprender como se faz o 'melhor avião de papel do mundo', um chapéu, um barco e uma bomba d'água de papel. $E$ também, incursionando pelo mundo da eletricidade, poderão aprender a fazer uma pilha, uma lanterna de bolso, temporizadores e fios disparadores e um eletroímã simples (lembremos o quanto o mundo da tecnologia tem sido caracterizado como masculino). Há também ensinamentos que remetem ao mundo do escotismo e das aventuras off-road; assim, afirma-se que todo o garoto deveria conhecer 'cinco nós', assim como pode aprender a fazer uma 'atiradeira'. Como construir uma casa na árvore é outra sugestão cuja dificuldade é enfatizada, mas que, por outro lado, é descrita como possibilitando 'uma das melhores coisas que se pode ter'. E mais: o livro ensina 'como fazer arco-e-flecha', 'como fazer um carrinho', 'como construir uma bancada de trabalho', 'como fazer cristais', 'como fazer malabarismo', como fazer 'pano à prova de fogo', 'tinta invisível', 'projetor', 'periscópio', 'como fazer um embrulho com papel pardo e barbante', 'como ensinar truques caninos', 'como fazer pedras ricochetearem n'água', 'truques com moedas'. Já a abordagem da técnica da 'marmorização' incorpora um raro trabalho manual não marcadamente masculino que é ensinado aos meninos.

Também se informa e se ensina sobre outras práticas cotidianas, geralmente ligadas ao masculino, como a pescaria, e inúmeros jogos de mesa: futebol de botão, sinuca, bilhar, pinguepongue; pôquer, xadrez; jogos com lápis e papel: forca, jogo da velha, stop, batalha naval; jogos de bolinhas de gude e informações básicas sobre os contemporâneos RPG. Deve-se lembrar, ainda, a abordagem das 'regras do futebol' -lembremos o quanto os estudos mostram como o futebol é o esporte de forte tradição masculina. 
No que diz respeito à jardinagem, que veremos bem desenvolvida no manual para as meninas, apenas um item é privilegiado no livro para meninos - 'como cultivar girassóis'.

E o que se ensina para as meninas?

Sob o título geral 'Agulha e linha', abrem-se os ensinamentos de 'como fazer' para as meninas leitoras, ainda que as autoras sintam necessidade de justificarem a sua inclusão na contemporaneidade:

"No passado, fazia parte da educação das meninas aprender a costurar, bordar e dominar outras técnicas manuais. A revolução feminista e a luta por igualdade entre os sexos, porém, associaram a essas atividades o rótulo de "coisa menor", sem utilidade. Depois de séculos dedicados às agulhas e linhas e às tarefas "do lar" -enquanto os homens iam batalhar pela sobrevivência da família- as mulheres deixaram suas caixas de costura de lado e se juntaram aos parceiros. 0 resultado foi o aumento da rede doméstica, mas também o abandono dos pequenos prazeres que fazem parte do universo feminino desde o tempo das bisavós" (MLMa, 2008: 8).

E é sob o signo do prazer e, às vezes, das vantagens econômicas, que se seguem aulas escritas sobre pontos e técnicas específicas de costura, sobre como pregar botões, como fazer barra, tricô, etc. Já sob o título 'No Quintal', ensinam-se técnicas básicas de jardinagem, desde o escolar 'pé de feijão' no algodão, até o cultivo de flores e... temperos. Observe-se que, ao final da seção, há uma matéria sobre o 'significado das flores', como 'violeta/amizade, gardênia/ juventude', e, especificamente, os significados das cores das rosas, flor essa que é lembrada como 'sinônimo de amor'. Cuidados com o jardim reaparecem nas partes dedicadas ao outono, ao inverno e à primavera.

Já a seção 'Na cozinha', iniciada com Regras de ouro, segue com sugestões para 'preparar um café-da-manhã caprichado', com receitas fáceis de ‘Delícias salgadas’ e ‘Delícias doces', bolos, sanduíches, sucos e biscoitos. Em outras seções do livro, também comparecem receitas, como as 'bebidas refrescantes', para a vida 'perto do mar', as 'delícias assadas' para acampar, as 'receitas para o lanche', no friozinho do outono, 'ovos de Páscoa', por ocasião da Páscoa, 'chocolate quente' no inverno, 'musse de maracujá' na primavera, etc. Observe-se que a habilidade em trabalhos manuais, em especial voltada à decoração doméstica, também é requisitada em várias passagens do livro, como para fazer ovos marmorizados, desenhos de folhas e pétalas, coletar folhas caídas e arrumá-las, etc.

Como o livro para meninas está, 'a grosso modo', organizado em torno das estações do ano, muitas lições estão condicionadas a tal organização: dicas para fazer um piquenique (preparativos, comidas e lanches, etc.) e para ir a um parque, no verão. 0 interessante é que, ao 
lado das dicas práticas, são colocadas informações que dizem respeito ao mundo da imaginação, da sensibilidade, digamos, como as informações sobre a 'Morada das fadas' e sobre como encontrá-las no parque! Outras brincadeiras caseiras e sossegadas, como adivinhações, são sugeridas no outono.

A exemplo do livro para meninos, também há dicas e ensinamentos sobre jogos e brincadeiras, e, num primeiro momento, se privilegiam brinquedos tradicionais como 'queimada', 'amarelinha', 'cabra-cega', 'pular corda'. Na seção 'Vida ao ar livre', é que as meninas são desafiadas para maiores ousadias; aborda-se a "arte de cair" como prefácio à abordagem de como 'subir em árvores' (seria para visitar os garotos que construíram casas sobre as mesmas, conforme o manual dos meninos?) e fazer escaladas. Abordam-se também as 'brincadeiras com bola' (observe-se que, para os garotos, o termo preferido é 'jogos' e não 'brincadeiras') e esta seção vem precedida por um moderado brado de guerra feminista: 'Quem disse que bola é para meninos? As garotas, hoje, são presença constante nas quadras de diversos esportes por muito tempo considerados 'masculinos', como o 'basquete' e o 'futebol'. 0 interessante é a justificativa trazida pelas autoras para motivar as meninas a aprenderem mais sobre tais 'modalidades esportivas': 'Algumas modalidades esportivas são ótimas para manter a forma e treinar o espírito de equipe'.

Cuidar e relacionar-se com animais domésticos e não apenas treiná-los para fazer truques (com o cachorro), como é sugerido no manual para meninos, é outro ensinamento do livro para meninas, mas seguramente o espaço para esse tópico é exíguo se comparado às várias páginas reservadas para o desenvolvimento do tópico ‘Beleza e Maquiagem'. Nesse último caso, as autoras se apressam em apresentar a possibilidade de eventuais reservas das mães das leitoras sobre maquiagem (afinal, essas meninas não são as que levariam seus bichos de pelúcia para o piquenique?). A pele, os lábios e faces, o rosto, os olhos, as sobrancelhas, assim como todo o tradicional arsenal de maquiagem feminina -sombras, batons, rímel, base- recebem a atenção das autoras. Na mesma trilha -da beleza e da aparência pessoal- vêm lições básicas sobre balé, que são seguidas, no livro, por uma seção sobre 'Apresentações', algo assim como sugestões de saraus de música clássica, de dança moderna, de musicais caseiros ou, ainda, de uma peça de teatro a ser feita pela própria leitora. É interessante registrar que as autoras apostam nessa possibilidade - de escrita de uma peça de teatro pelas leitoras- de forma tão entusiasmada quanto os autores do manual para garotos parecem ter se entusiasmado ensinando meninos a fazerem uma casa sobre uma árvore!

Voltando ao tópico da beleza e aparência pessoal, os cabelos -estilos, cortes, cuidados, curiosidades e dicas- serão objeto de 14 páginas do livro, as quais serão seguidas por 10 páginas dedicadas a perfumes: tipos, como preparar alguns e como usá-los. Mas as meninas também 
deverão saber organizar festas, desde a elaboração de convites, a decoração do ambiente, as indefectíveis comidas e bebidas, a escolha de temas, as brincadeiras para animar, etc. Para cada data festiva em especial -Páscoa, Natal, festas juninas- haverá ensinamentos específicos para que a garota se prepare desde cedo para capitanear, em sua casa, os preparativos correspondentes.

E, como também se espera das mulheres um exercício mais completo da civilidade, o manual das garotas, quase ao seu final, traz 'dicas valiosas' sobre como se comportar em várias situações, desde visitas a casas de amigos, busca de banheiros em viagens a países estrangeiros, como comer pão, espaguete e tomar sopa. Alguns apontamentos sobre 'o mundo da amizade', a escrita de um diário, como guardar um segredo, conviver com seu próprio mau humor, ser fã de um ídolo da mídia fecham o livro, no que diz respeito aos ensinamentos do 'fazer'.

\section{0 que é bom para meninos e o que é bom para meninas -quais assuntos são de seu interesse?}

Num segundo momento, podemos examinar as áreas que são privilegiadas como temas de interesse para a formação dos meninos e das meninas, de tal forma que foram inseridos textos informativos sobre as mesmas. No caso do LPGo (2007), avultam, em primeiro lugar, alguns temas de História Geral e do Brasil, como 'As sete maravilhas do mundo antigo', 'Batalhas famosas da Antiguidade', 'Batalhas famosas da modernidade', 'Batalhas famosas do Brasil', temas completados -no terreno bélico- por uma 'Breve história da artilharia'. Além de uma síntese da História do Brasil ('Brasil -uma breve história'), encontramos textos com histórias heróicas de cunho individual: ‘A conquista do pólo sul’, 'O viajante solitário’ (Amyr Klink), ‘A época de ouro da pirataria’; 'Uma aventura no céu’ (Santos Dumont); ‘Mistério na selva!' (a história de Fawcett) e 'Os irmãos Villasboas e a marcha para o Oeste'.

Também a Astronomia é contemplada, com textos sobre o estudo dos céus, navegação aérea, mapas estelares e o sistema solar. É importante registrar que os autores afirmam peremptoriamente: "Astronomia não é astrologia. Astrologia é bobagem" (LPGo, 2007: 120), o que pode ser cotejado com as informações dadas para as meninas no manual a elas dirigido, como veremos adiante.

Mas os interesses científicos e informativos dos meninos são representados, ainda, como mais amplos. Temos, assim, textos que abordam questões geográficas (latitude e longitude, mapas, 'Sete maravilhas do mundo moderno', marés, duração do dia, ventos), meteorológicas (sobre nuvens, por exemplo), paleontológicas (fósseis, dinossauros), físicas (luz, por exemplo) e bio- 
lógicas: insetos (incluindo a barata, com ilustrações, tema que seria improvável no livro para meninas). Insere-se, ainda, uma abordagem francamente tradicional da gramática, em três partes, que contém afirmações do tipo: "Se você ouvir alguém dizendo 'entre você e eu', não é questão de opinião, está errado" (LPGo: 2007: 65). Por fim, registre-se a inserção de temas religiosos ('Os Dez Mandamentos') e curiosidades ligadas à espionagem e a códigos: 'espiões: códigos e cifras' e 'Código naval de bandeiras'.

Já no livro dedicado às meninas, os assuntos privilegiados são de âmbito mais restrito -há, decididamente, menos temas científicos- e guardam um outro tom. Em primeiro lugar, há vários destaques espalhados pelo livro contendo o que se chama de Curiosidades, que são curtos itens cujo tema está relacionado à seção prática em que se localizam. Na seção dedicada a 'Acampar', por exemplo, as curiosidades estão ligadas ao fogo, à fogueira, à festa de São João (MLMa, 2008: 88); na seção sobre 'De olho nas estrelas', encontram-se informações sobre leitura do céu, numa abordagem bem mais simplificada do que a feita para os garotos. Na seção dedicada a animais de estimação, as curiosidades contemplam características corporais e funcionais dos gatos e dos cachorros, assim como informações sobre cavalos famosos e a reprodução dos Direitos dos Animais. Na seção sobre Teatro, também se informam nomes e autores de peças teatrais de cinco peças brasileiras. Seção que está presente no manual para meninas e não tem similar no livro para garotos é a que diz respeito a Festividades e Comemorações - Carnaval, Festas juninas, Dia das Bruxas, contendo algumas dicas correlacionadas aos festejos. Também o Natal merece uma referência especial, mas suas curiosidades abrigam informações como os nomes das renas do Papai Noel.

Há algumas seções bastante especializadas e (MLMa, 2008: 262 e seguintes) podemos adentrar o mundo da 'Leitura da Sorte', incluindo a Leitura das mãos, os signos do Zodíaco, a sorte no papel e como criar um oráculo. Estamos, sem dúvida, bem distantes da decidida condenação da Astrologia do manual para garotos.

Para as leitoras, há sete itens que pertencem a uma mesma seção, denominada 'Mulheres inspiradoras', onde vamos encontrar tanto personalidades brasileiras, como Nise da Silveira, médica pioneira no tratamento de doentes mentais; Leila Diniz, atriz irreverente e contestadora de tabus sociais dos anos 60 e 80; Chiquinha Gonzaga, musicista e compositora pioneira na música popular brasileira; Anita Garibaldi, conhecida como a heroína de dois continentes, as 'musas das artes' da mitologia grega; Rosa Parks, militante de organização de defesa dos direitos dos negros americana, e, finalmente; Ana Néri, primeira enfermeira brasileira. É interessante registrar o quanto algumas dessas 'Mulheres inspiradoras' poderiam inspirar -pelo que se conhece de suas vidas- atitudes e ações muito diferentes das sugeridas nas restantes páginas do manual. 
Outra seção que se repete em várias passagens, é a de Grandes Amores, em que são focalizadas Helena de Tróia, Romeu e Julieta, Marco Antonio e Cleópatra, Dom Pedro e Inês de Castro, Lampião e Maria Bonita. Nada há de semelhante no livro para meninos. 0 que há de comum entre os dois -de forma clara- é a parte dos Primeiros Socorros.

\section{0 que é bom para meninos e o que é bom para meninas -sugestões de leituras, filmes e músicas}

Por fim, nos deteremos, nas sugestões que os autores fazem aos leitores e leitoras, no que podemos chamar de produtos culturais (filmes, livros, etc.).

Entre os 'Quadrinhos que todo garoto deveria ler', estão heróis como X-Men, Batman, o HomemAranha e também os clássicos: Asterix, Peanuts, Tintim, Mafalda, além das irreverências de Mad. Já os 'filmes que todo garoto deveria ver' compreendem a indicação de 20 títulos: filmes de ficção científica, como 'Guerra nas Estrelas', faroestes, filmes de espionagem, policiais, de suspense ('O enigma da pirâmide'); filmes de aventura, como Super-homem, Indiana Jones, 'De volta para o futuro'; comédias como 'O trapalhão nas minas do Rei Salomão', 'Curtindo a vida adoidado'; filmes de terror ('A noite dos mortos vivos'), alguns desenhos (Toy Story, Shrek), ao menos um filme romântico -'Houve uma vez dois verões' - e um filme mais voltado para meninos adolescentes - 'Conta comigo'- além de títulos considerados clássicos para crianças como ET e Peter Pan.

Já os 10 filmes indicados para as meninas não coincidem com qualquer sugestão para os meninos, privilegiando tal lista os títulos românticos e os de formação; assim, temos desde ' $E$ o Vento levou...' até 'Orgulho e Preconceito', passando pelo desenho romântico de Disney 'A Dama e o Vagabundo' e por uma adaptação de Louise May Alcott, 'Adoráveis Mulheres'. 0 interessante é que as autoras do manual (ou a editora) lançam mão de ícones (desenhos) que indicam a presença de: 'tema feminino', 'romance', 'choro', 'estrelas', ‘bonitões’ para classificar suas indicações.

A leitura das sugestões de 'Livros que todo garoto deveria ler' nos mostra a presença de alguns marcadamente infantis, como Contos de Fadas, poemas de Pedro Bandeira (autor brasileiro contemporâneo), Sítio do Picapau Amarelo (Monteiro Lobato, maior escritor infantil brasileiro), As viagens de Gulliver, algumas histórias fantásticas, aventuras, ficção científica, histórias de mistério, não se registrando nenhuma leitura com temática amorosa.

Com 'Cinco poemas que todo garoto deveria conhecer' os autores do livro para garotos de certa forma quebram um tabu de gênero freqüente -o de que homens, meninos, rapazes não apre- 
ciam poesia e que poesia é 'coisa de mulheres'. Talvez esta seja a mais importante ruptura na representação de gênero masculino em todo o livro. Inclusive, os autores exortam os leitores: "Sim, você pode passar toda a sua vida sem tomar conhecimento de qualquer poema. Mas seria uma pena... Experimente, lendo os seguintes poemas" (LPGo, 2007: 224). E um deles é um clássico da poesia amorosa brasileira - 'Soneto de fidelidade', de Vinícius de Moraes. Completando o repertório cultural que os autores propõem para seus leitores, encontramos as 'Expressões latinas que todo garoto deveria conhecer' (um tributo à tradição?) e uma discoteca básica, com vinte 'grandes discos de rock', dizem os autores (nada de música romântica...).

Já as indicações para a formação cultural da menina -mais restritas- vêm enfeixadas, em sua maioria, nas 20 páginas sob o título 'Um pouco de cultura', em que se indicam 17 livros de gêneros variados (poemas, livros infantis, romances e novelas clássicas para adolescentes, ficção científica, etc.). Um confronto com as 20 indicações do livro para meninos permite verificar a coincidência de indicação de Monteiro Lobato, de 'As Aventuras de Tom Sawyer' (Mark Twain) e de 'O Leão, a Feiteiceira e o Guarda-Roupa', de Lewis. Por outro lado, as meninas recebem indicações tradicionalmente mais 'femininas': 'Pollyana', 'Mulherzinhas' e 'O Pequeno Príncipe'. Já as poesias para as meninas vêm inseridas dentro da seção 'Um pouco de poesia', e compreendem -apenas- o Soneto 17, de Shakespeare (no verão), 'Canção do outono’ de Mário Quintana, poeta brasileiro do século XX.

Além dos apontamentos comparativos já feitos, poderíamos acrescentar algumas anotações neste momento. Assim é que a escolha das áreas em que aparecem os ensinamentos de 'como fazer' mostra uma marcada divisão por gênero social: enquanto que, para as meninas, avultam as lições sobre 'prendas domésticas' (costura, culinária, jardinagem, decoração), cuidados pessoais e beleza, atividades artísticas, para os meninos a tônica é nas atividades 'masculinas', ou de marcenaria, ou de eletricidade, ou, ainda, aquelas que demandam vigor físico e coragem, e que se exercem frequentemente no espaço público.

Também as temáticas dos textos informativos diferem -para os meninos, batalhas e aventuras intrépidas (com homens); para as meninas, histórias de amor. Para os meninos, investimento pesado em conhecimentos das chamadas ciências duras ou escolares, em geral; para as meninas, astrologia, leitura de mãos, apelos à sensibilidade. Para os meninos, uma ênfase maior em produtos culturais (filmes, livros) com a tônica de aventuras, mistério, ação; para as meninas, além de eventuais indicações de aventuras e ficção, também romance e temáticas sentimentais.

Antes de encerramos o paralelo dos dois livros, alguns pontos ainda podem ser enfatizados. 


\section{Amizade e relações com o sexo oposto nos dois manuais}

Em primeiro lugar, deve-se registrar, no livro para meninas, a insistência da referência à leitora e suas 'amigas'. Assim, (MLMa: 2008: 55) as autoras sugerem: "Que tal convidar suas amigas para um chá da tarde?" ou uma curiosa sugestão para o piquenique: "Se você quiser 'convidar' seus bichos de pelúcia e bonecas para o piquenique, não se acanhe. Melhor ainda: diga para suas amigas fazerem o mesmo" (MLMa: 2008: 63). Também às páginas 128 e 149, há questões idênticas: "Mas quem disse que juntar as amigas para apresentar uma peça de teatro ou um musical não pode ser divertido?" / "Com mais algumas amigas (ou apenas uma) dá para improvisar uma sessão de adivinhações”. Assume-se, assim, que o 'natural' das meninas leitoras seja a convivência entre pares do mesmo gênero. Entretanto, em algumas passagens abre-se a possibilidade da convivência entre garotos e garotas, como no caso do jogo 'Queimada', em que se afirma: "Meninas e meninos podem brincar juntos e, quanto mais disputada a partida, maior a diversão" (MLMa: 2008: 67). Finalmente, assume-se a oposição marcada: "Você quer fazer uma festa que agrade aos meninos?” (MLMa: 2008: 212) (obviamente, a resposta é a realização de uma festa com o tema 'futebol').

E é necessário, também, focalizar as seções -nos dois manuais- em que os autores e autoras trazem lições sobre o 'sexo oposto'. Sob o singelo título 'Meninas', os autores do manual para garotos iniciam a abordagem do tema com uma afirmação persuasiva sobre as diferenças entre meninas e meninos: "Talvez você já tenha notado que as meninas são bem diferentes de você" (MLMa: 2008: 137). Seguem, então, oito interessantes (e bem humorados, é preciso dizer) conselhos do bom relacionamento, em que as meninas são representadas como sujeitos que falam muito de si ('Uma piada só, talvez, e depois o longo silêncio enquanto ela fala de si mesma...'), asseadas e arredias a coisas nojentas (essas, comuns entre os garotos), apreciadoras de meninos com "brilho corado" e dignas de 'respeito'. É necessário observar que os autores parecem acentuar mais o constrangimento dos meninos frente às meninas do que qualquer outro traço.

Já no manual para meninas, também encontramos uma seção denominada 'O mundo dos garotos' que inicia com as seguintes afirmações:

“A grande diferença entre meninos e meninas é que os garotos gostam de 'fazer' coisas -dirigir carros, jogar bola, brincar, comer, soltar pum etc.--, enquanto as garotas gostam de "sentir" coisas -amor, amizade, felicidade, entusiasmo etc. As meninas são mais emocionais do que os meninos. É claro que não se trata de uma regra absoluta: um garoto pode muito bem demonstrar mais sensibilidade, só que isso não é muito comum" (MLMa: 2008: 290). 
As dificuldades de comunicação constituem um dos traços marcantes atribuídos aos meninos, eventualmente, eles podem apresentar 'imaturidade', não notar que algo está incomodando as meninas, ser inseguros ('são tão inseguros quanto qualquer garota'), sequiosos de elogios sobre suas habilidades. $E$, entre os conselhos, um nos chama a atenção em especial: é aquele que avisa às leitoras que 'Alguns garotos (mal acostumados pelas mães), podem acreditar que todas as coisas chatas da vida devem ser feitas por garotas', arrolando-se as tais coisas chatas: 'limpar a casa, lavar e passar roupas e cozinhar'. E prosseguem as autoras: 'Para eles, restam as coisas boas: esportes radicais, bandas de rock e brincadeiras ousadas'. Uma exortação arremata tal conselho: 'Não deixe que essa tendência aumente!'

Pois bem: tal conselho, de cunho feminista, pode parecer um tanto exótico ao final de um manual para meninas, onde abundaram as receitas de cozinha e de decoração, os conselhos de beleza, e raras foram as menções a esportes radicais (subir em árvores e escalar foi o que se indicou neste campo às garotas), a bandas de rock (os meninos receberam indicações de discos de rock, mas as meninas, não) e atividades mais ousadas.

\section{CONSIDERAÇÕES FINAIS}

0 percurso analítico que acabamos de fazer nos permite propor algumas conexões com as discussões inicialmente feitas. Assim é que a análise dos dois livros permite que os entendamos -quando vistos de maneira global- como 'livros contemporâneos de auto-ajuda', espécie de manuais contemporâneos de civilidade. Nesse sentido, eles incorporam discursos que 'oferecem saberes e deveres idealizados' (Costa, 2008), neles predomina 'a cena enunciativa de aconselhamento' e, sem dúvida, há todo um movimento no sentido de que os leitores aceitem determinados valores sociais. Estabelece-se, também, tanto nos paratextos iniciais, como em comentários introdutórios às seções, a credibilidade e a autoridade dos autores (para os garotos) e das autoras (para as garotas). Por outro lado, percorrem os textos de ambos os livros as interpelações diretas: "Se você quiser aprender o significado do amor incondicional..." (MLMa, 2008: 96), "Prepare seu projetor e aproveite a ocasião" (LPGo, 2007: 207), por exemplo, evidenciando o caráter injutivo do gênero textual.

Ao final da análise, certamente podemos retomar o argumento central deste estudo, qual seja o de que o gênero social marca de forma diferenciada o gênero discursivo. As representações de meninas e meninos que são projetadas pelas escolhas das áreas de atividades práticas, dos campos de informação e, mesmo, dos tópicos do que chamamos de 'aperfeiçoamento cultural' vêm ao encontro do que a literatura sobre gênero social aponta como socialmente atribuído como natural ao masculino e ao feminino. Assim, Mazzara (1998: 22) observa que, de maneira 
geral, as mulheres têm sido consideradas como "mais emotivas, amáveis, sensíveis, dependentes, pouco interessadas na técnica, cuidadosas de seu aspecto, naturalmente solícitas", enquanto os homens são vistos naturalmente como "agressivos, independentes, orientados para o mundo e para a técnica, competitivos e seguros de si mesmos, pouco emotivos". Se, nos livros que analisamos, a questão da 'segurança' dos meninos não é taxativamente afirmada, deve-se, provavelmente, ao público a quem ambos se dirigem -garotos e garotas a partir de oito anos.

Enfim, tais livros -ainda que contenham ressalvas sobre as mudanças do mundo contemporâneo e, no caso do manual para as meninas, façam, inclusive menções à 'revolução feminista' e tragam, entre os perfis de 'Mulheres Inspiradoras', brasileiras que constituem ícones da independência feminina e da contestação de valores tradicionais, como Leila Diniz e Chiquinha Gonzaga- estão contribuindo para reafirmar a dicotomia de gênero ainda calcada em binômios tradicionais: sentimento/razão; espaço doméstico/espaço público; sensibilidade/valentia; comunicabilidade/rudeza. Nesse sentido, vale a pena relembrar os efeitos de constituição identitária de tais estereótipos, que reapareceram, por exemplo, em produções escritas de alunos brasileiros do ensino fundamental, quando solicitados a escreverem sobre um passeio escolar, conforme estudo realizado por Silveira e Santos (2004). A partir da análise de 100 textos escolares, oriundos de 70 diferentes municípios brasileiros, foi possível às autoras identificarem a recorrência da divisão das atividades e características de meninos e meninas. Conforme as autoras (Silveira \& Santos, 2004: 270):

“(...) no mundo re-criado nas redações, as meninas realizam atividades como tomar banho de sol, dançar, jogar vôlei e basquete, brincar de roda, de casinha, de pegar, andar em balanços e gangorras, pular corda (...). Ficam deitadas no parque, além de correrem e fazerem ginástica (...). [também] encontramos nos textos a referência a que a professora, as meninas ou o grupo das "mulheres" prepara lanches e refeições para todo o grupo".

E as redações ainda nos contam sobre meninos que jogam bola, futebol, brincam de correr e pescar (lembram que a pesca é abordada apenas no manual para meninos?), pegam animais nojentos para assustar as meninas, se envolvem em aventuras e perigos. Além disso, as referências, nos textos das crianças, são a agrupamentos separados de meninos e meninas, como, aliás, está pressuposto em várias passagens dos dois manuais que acabamos de analisar.

0 que pretendemos, ao cotejarmos textos elaborados por crianças de $4^{\mathrm{a}}$ ano do ensino fundamental -a maioria, de pequenas cidades do sul do Brasil- com dois manuais de auto-ajuda para meninos e para meninas que nos chegam da Inglaterra, em adaptação, é mostrar o quanto determinadas representações de gênero social atravessam fronteiras geográficas, culturais, sociais e temporais, repercutindo, inclusive, na produção de textos de um determinado gênero discursivo -a auto-ajuda para crianças e pré-adolescentes. 


\section{REFERÊNCIAS BIBLIOGRÁFICAS}

Carvalho, J. (2009). O compêndio dos salesianos [em línea]. Disponível em: http://www.cinform.com.br/blog/impressao/9521

Costa, S. (2008). Dicionário de gêneros textuais. Belo Horizonte: Autêntica.

Davidson, R. \& Vine, S. (2008). O maravilhoso livro das meninas. São Paulo: Globo.

Elias, N. (1994). O processo civilizador. V.1: Uma história dos costumes. Rio de Janeiro: Zahar Editores.

Hallewell, L. (1985). O livro no Brasil. São Paulo: T.A. Queiroz: Ed. da USP.

Iggulden, C. \& Iggulden, H. (2008). O livro perigoso para garotos. Ed. Rio de Janeiro: Galera Record.

Mazzara, B. (1998). Estereótipos y prejuicios. Madrid: Acento Editorial.

Meurer, J. L. (1998). Aspects of language in self-help counselling. Florianópolis: UFSC.

Postman, N. (1999). O desaparecimento da infância. Rio de Janeiro: Ed. Graphia.

Silveira, R. \& Santos, C. (2004). Gênero e diferença em textos escolares infantis. Em Carvalho, M. \& Rocha, C. (Orgs.), Produzindo gênero (pp. 267-277). Porto Alegre: Sulina. 